\title{
LEARNING FROM THE PRESENT AND THE PAST: A CONTEMPORARY AND HISTORICAL REVIEW OF AGRICULTURAL IMPACTS ON SOIL FERTILITY
}

\author{
Leslie Campbell \\ Department of Physical and Environmental Sciences, University of Toronto, \\ Scarborough, 1265 Military Trail, Toronto, ON, M1C 1A4 \\ lesliecampbell@gmail.com
}

\begin{abstract}
ABSTRAK
Conventional farming involves the use of synthetic and chemical pesticides that increases the short-term productivity of the soil with the expense of its long-term fertility. The emergence of alternative agriculture movement is estimated to have become a progressive response in increasing awareness of the long adverse effects on effort to promote the soil which is well cultivated by agro-ecological environment. Although it is a shift from conventional farming, alternatative farming practices have not been adequately integrated as organic farming techniques and remain non organic farming options. In an effort to explore the differences, we conducted a literature review of temperate areas studies comparing to conventional and alternative farming techniques in terms of their effects on soil nutrient levels. This review was found that $70 \%$ of the literature supports the use of alternative techiques as the means of reducing the agriculture impact on fertility and health of soil and haiglights the need of further research on topic of longitudinal studies primarily in context of ecology of temperate climate. To contextualize contemporary view with the developing popularity of alternative conventional farming system, we also explored the literature about the impact of agriculture that expanded again from 1920s. Historical study examined literature concerning with long-term fertility soil in Canada Journal on scientific agriculture to capture general environment narration about alternative farming at that time. It was found that a segment of the pre-1950s literature viewed the farming practices sustainable time, citing the declining yields to support this claim. The latest increasing proved in alternative farming techniques in response to a growing awareness of the long-term effects of convenstional farming can be contextualized in the context of history as well as the rise of a more traditional approach to farming.
\end{abstract}

\section{Keywords: conventional farming, organic farming}

\section{INTRODUCTION}

Since the green revolution of the 1950s and $60 \mathrm{~s}$, the rate of agricultural production has been on the rise (1) (2). Increased access to high yielding plant varieties, synthetic chemicals and fertilizers meant that agriculturalists could increase their production efficiency thus producing more food on less land than ever before. This led to the advent of what is now known as "intensive" or "conventional" agriculture (1). Typically, conventional agriculture refers to a large scale, capital intensive, highly mechanized form of agriculture 
involving the extensive use of artificial fertilizers and crop monocultures with the sole aim of maximizing yields (3). This is the dominant approach employed by most Western national governments, farmers and agribusiness groups but intensive agriculture is also becoming increasingly common in developing countries (4), especially among farmers with access to the necessary capital and technological inputs (5). Unfortunately, these increased yields come with a price. Over time, the use of intensive agriculture techniques have led to regional pollution, increased erosion and decreased soil fertility. As a result, there are currently growing concerns about the long-term sustainability of these techniques given the context of rising global populations and increasing demands for food (2).

In response to these concerns, alternative agriculture presents another option for meeting the food needs of our growing population while also addressing the need for long-term maintenance of soil fertility. The term 'alternative', referring to anything different from the usual or conventional (6), is commonly used to describe recent shifts toward techniques that emphasize long-term social, environmental and economic viability, but lacks a universally accepted definition (7) (8). For the purposes of this paper, the term 'alternative agriculture' refers to agricultural systems that share various broad goals including long-term sustainability through soil maintenance and resource conservation, healthy food production, and protection of environmental value (9).

The ideology behind alternative agriculture is not a new one. Alternative agriculture techniques can be similar to those of more traditional forms of agriculture practiced before the advent of industrial processes and synthetic agricultural inputs (10) as well as ecological intensification which employs more rigorous use of ecological principles to maintain soil fertility and long-term agricultural production (11) (2). Therefore, the recent increase in the prevalence of alternative agriculture techniques in response to a growing awareness of the long-term impacts of conventional agriculture should not be seen as a new development, but as a resurgence of more traditional approaches (12).

\section{Alternative agriculture}

Alternative agriculture approaches are strongly connected to those of organic farming (9). Organic farming is defined by the FAO as a holistic management approach to agricultural production, which focuses on the maintenance and enhancement of agroecosystem health. It advocates for the replacement of off-farm inputs with careful, locally adapted systems that take into account regional conditions. This is done using biological, mechanical or agronomic methods instead of synthetic materials to fulfill the functional needs of agricultural systems (13).

Another alternative approach is bio-dynamic farming, an ideology that views the entire agricultural system as a living entity. Biodynamic farming methods are very similar to those of organic agriculture, in that biodynamic farming does not involve the use of artificial inputs. Bio-dynamic systems also incorporate mystical, spiritual and astrological aspects such as the movement of the moon and the planets in the farming process (4). These are used to choose when crops are planted and harvested, and govern which non-synthetic treatments are used on which plant species.

Although alternative approaches to agriculture have been the target of significant research and development, conventional techniques continue to be the most common forms of agriculture and currently pose a significant threat to the food security of a large portion of the global 
population as a result of their long-term detrimental effects on soil fertility and environmental health. In an effort to quantify the benefits of alternative techniques, numerous studies have examined their ability to maintain soil fertility. The measurement and analysis of soil nutrient levels over time in conventional versus alternative agricultural systems allows for a direct comparison of the two classes of agricultural techniques.

\section{Trends in temperate agriculture and soil fertility}

This paper reviews the current literature on conventional versus alternative agriculture techniques in terms of their effects on longterm soil fertility by comparatively analyzing soil nutrient status over time. In doing so, we hope to comparatively demonstrate the long-term beneficial effects of alternative farming practices on soil health. Soil nitrogen $(\mathrm{N})$, phosphorus (P) and potassium $(\mathrm{K})$ levels were used as indicators of soil fertility. Focusing exclusively on these three identified soil fertility indicators allowed us to narrow the scope of comparison, however, we recognize that it also limits the use of other parameters such as soil structure, microbial activity and organic carbon levels in interpreting the results of selected studies. We focus our attention primarily on comparative studies originating from temperate ecoregions across the USA, central and northern Europe and New Zealand. One relevant study was carried out in the subtropical ecoregion and was included to demonstrate that many of the results discussed herein are not confined to temperate crops or farming systems. The dominant agricultural crops of interest in this review are wheat, barley, corn, clover and soybean.

In an effort to properly contextualize both contemporary views and the burgeoning popularity of alternatives to conventional agricultural systems, our study also includes an exploration of historical perspectives on the detrimental impacts of agriculture extending back to the 1920s. To capture the general environmental narrative regarding agriculture at the time, we analyze sections of the relevant historical literature and use these texts to contextualize current views on organic versus conventional agriculture systems.

\section{Comparative review of agriculture management consequences}

We examined 10 contemporary studies published between 1991 and 2007, which were based on both field trials and on static soil nutrient measurements taken from preexisting conventional and organic plots. The field trials ranged in duration from 4 to 21 years and included examinations of conventional, organic and bio-dynamic farming systems all but one of which operate in temperate regions. In this study, we focus on the measurement of three parameters in the literature: nitrogen $(\mathrm{N})$, phosphorus $(\mathrm{P})$ and potassium $(\mathrm{K})$. Although the concept of soil fertility status as an indicator of soil health is explored extensively elsewhere by (14), assessment of soil nutritional status is a common method of measuring overall soil fertility and health. Of the 10 studies we reviewed comparing soil nutrient levels between organic and conventional agriculture systems, 9 utilized soil $\mathrm{N}$ as an indicator of fertility, 4 examined soil $\mathrm{P}$ and 2 used soil K. The majority of these studies support the hypothesis that the use of alternative farming methods maintains the naturally occurring levels of these nutrients in the soil more effectively than conventional management practices (15) (16)(17) (18) (19) (20) (21). While inorganic fertilizers provide a short-term increase in soil nutrient levels, these nutrients are easily leached from the soil, especially when used in conjunction with heavy irrigation which is 
another common practice in conventional farming systems (22). Chemical pesticides also adversely affect soil health by reducing the number and diversity of soil faunal populations compared with conventional systems, which indirectly effects soil health by impeding soil nutrient cycles and retarding the breakdown of soil nutrients (23) (24).

Although the results of the reviewed contemporary studies were largely consistent, the methodology and duration of the studies varied considerably. We classified the studies by duration, labelling those that examined alternative agricultural systems that had been operating for under 10 years as "short-term studies" and those greater than 10 years as "long-term studies".

\section{Short-term studies}

Just over $25 \%$ of the short-term studies we examined used a trial-based approach in which various treatments mimicking conventional or alternative agricultural techniques were applied to crops and the resulting changes in soil fertility were monitored and compared. These studies all took place in the USA and employed multiple fertility treatments examining wheat, corn, bean, safflower and tomato crops. They consistently found that a combination of alternative agriculture techniques such as the planting of cover crops, no-till crop rotations, reducing levels of chemical fertilizer application and amending the soil with manure or other organic inputs led to increased soil total $\mathrm{N}$ levels following the trial period, when compared to conventional management practices (20) (21). One study also found that soil $\mathrm{P}$ and $\mathrm{K}$ had increased during the trial period as well, further reinforcing the evidence in support of alternative management techniques (20).

Alternatively, 4 of the short-term studies took an observational approach, examining various pre-existing conventional and organic farm sites instead of establishing various treatments. Soil fertility levels were measured in situ on the various farms, providing researchers with the long-term results of various farming practices without having to wait to set up and conduct the trials. Standard procedure for these studies was to examine soil nutrient levels in paired sets of conventional and alternatively managed farms that were as similar as possible in size and crop makeup (16) (18) (25). One of the studies took a slightly different approach, observing a set of 9 farm sites each with a comparison of conventional and alternative techniques on-site (17). This particular study also included data collection sites that had been operational for varying time period, but was considered a short-term study overall because the majority of them had been operational for less than 10 years. These observational strategies allowed for the isolation of management techniques as the independent variable affecting soil nutrient levels.

The results of the observational short-term studies were found to be the same as those of the trial based studies. It was found in all cases that total $\mathrm{N}$ and $\mathrm{P}$ levels had increased as a result of the alternative agricultural practices in comparison to conventional management (16) (18) (25) (17). Two of these studies also compared bio-dynamic farm systems to conventional methods, yielding very similar results to those of the organic farming trials, with greater longterm soil fertility in bio-dynamically managed plots (18) (25). This result was unsurprising, considering that bio-dynamic farming techniques are very similar to those of organic farming and adhere to many of the same tenants such as the closing of nutrient cycling and the use of no chemical pesticides or fertilizers. 


\section{Long-term Studies}

In our review of the literature, we classified studies of alternative agriculture systems that had been operational for more than 10 years as long-term studies. Forty percent of the studies examined fall into this category. These studies play an important role in supporting the push for the increased adoption of alternative agricultural practices, because they have the potential provide data that refutes the claim that the benefits to soil fertility observed in the short-term studies were temporary in nature. The long-term studies we observed ranged from 13-21 years and included both organic and biodynamic farming system comparisons (15) (19) (26) (23). Surprisingly, all of the longterm studies used a field trial design instead of observational techniques. This may be indicative of the fact there were much fewer pre-existing comparisons of alternative and conventional agricultural techniques when these trials were established, so in many cases agricultural researchers had no choice but to start their own.

The results of the long-term studies were much less consistent than those of the shortterm studies. Two of the studies reviewed focused on a single soil nutrient, and both found that nutrient to be higher in trials using alternative agriculture techniques, though due to their design it is difficult to state conclusively long-term term effects on soil health (15) (19). While both studies focused on bio-dynamic systems, the methodology was quite different. One study, a 13-year field trial comparison of biodynamic, bio-organic, conventional and control plots, focused solely on soil $\mathrm{P}$ levels(19). This study reported higher levels of organic $\mathrm{P}$ in the soil of both the biodynamic and bio-organic farming systems receiving no synthetic fertilizer inputs than those of conventional farms using synthetic fertilizers. This presumably indicates higher soil organic $\mathrm{P}$ through organic inputs in biodynamic and bio-organic systems.

The other study, by Fliebach et al (15), focused exclusively on $\mathrm{N}$ levels and had the distinction of having the longest running trials of any study we reviewed, collecting data from 5 different treatment sets over the course of 21 years. Field treatment methods were used to compare livestock-based biodynamic, bio-organic and integrated farming systems with a livestock-free mineral fertilizer conventional system and a control in which no soil amendments were used. This was the only study to examine an alternative system integrating crop production and livestock, which makes it difficult to contextualize its results. Data was collected over the trial period and consistently showed that bio-dynamic methods resulted in higher total soil $\mathrm{N}$ than organic methods, and significantly higher than $\mathrm{N}$ levels in the conventional farming trials. This likely indicates increased use of manure as organic fertilizer within the livestock based organic and bio-dynamic systems.

Yielding somewhat different results, Tong et al's(26) study of organic $\mathrm{C}$ and total $\mathrm{N}$ levels in rice paddy soils in Southern China found that the highest levels of total soil $\mathrm{N}$ were consistently found in fields with chemical fertilization plus high rates of organic manure. The authors used 4 field treatments over an 18 year period: no fertilizer, chemical fertilizer, chemical fertilizer plus low rates of organic manure, and chemical fertilizer plus high rates of organic manure. The researchers examined total soil $\mathrm{N}$ levels over time and found that the no fertilizer treatment fared the worst in terms of soil $\mathrm{N}$ accumulation, because the yearly harvest was consistently removing nutrients from the system without replacing them. However, as fertilizer application levels were consistent between the three chemical treatment plots, the rate of organic 
manure application becomes the driving treatment effect. In these trials, the soils with the highest rates of organic manure additions were also the soils with the highest total soil $\mathrm{N}$ over time. Interestingly, the trials using exclusively chemical fertilizer were found to contain the least total soil $\mathrm{N}$ at the end of the trial period (26). Despite its incorporation of synthetic crop amendments, this study can be interpreted as supporting the use of organic manure as opposed to chemical fertilizer as a means of maintaining higher levels of soil fertility, although it does not explicitly support the hypothesis that chemical fertilizers have a detrimental effect on soil nutrient levels over time.

Although the evidence of higher soil fertility levels in alternative systems over time is widespread, there were also studies that yielded the opposite results. A comparison of organic and conventional systems in a replicated field plot experiment by Mader et al (23) found organic systems to have lower levels of soluble $\mathrm{P}$ and $\mathrm{K}$ than conventional systems over a period of 21 years, but also found that the flux of phosphorus between the matrix and soil solution was the highest in bio-dynamic systems. The researchers measured a wide range of physical, biological and chemical soil parameters, and found levels of total $\mathrm{N}$ between the two systems to be very similar on average. The authors cite the decreased nutrient input levels in organic systems as the reason for these results. Other parameters such as faunal diversity and soil aggregate stability were higher in the alternative systems, but those parameters were not included as measures of comparison in this review.

The studies reviewed employ a wide range of methodologies, which arguably reduce the ability to compare their results. The incorporation of short-term and long-term timeframes, a range of alterative agricultural systems (bio-dynamic, organic, etc), and multiple types of experimental design (trial- based and observation) made it difficult to draw strong conclusions. This was most evident in our analysis of the long-term studies, the methodology and results of which varied much more so than those of the short-term studies. This points to a need for more longitudinal, system level studies of soil fertility between conventional and alternative systems to fill in the gaps in our understanding of the effects of these management techniques.

This being said, the variation in the number and type of studies included in this review was not without its benefits. In examining a wide variety of crops with varying nutrient requirements and yielding relatively consistent results, we can assume that this consistency was not due solely to the specific crop species examined. This provides confidence to the underlying commonality between the results of these studies that show bio-dynamic and organic farming methods to improve long-term soil fertility, despite their disparate methodologies.

\section{Historical trends in agriculture}

Although the current evidence is far from unanimous, due in part to the difficulty of finding comparable experimental conditions when conducting field trials, there is a growing body of evidence supporting the use of organic farming as a means of maintaining soil nutrient levels over time. This evidence has been used by supporters of the growing organic movement to reinforce their arguments for the increased use of alternative farming techniques to avoid the long-term detrimental effects of conventional agriculture on the soil (27). However, the ideas of today's organic movement are not novel or unique, but have actually been put forth by proponents of organic agriculture for many years. In an effort to explain how the debate for and against alternative agriculture has arrived at 
the current conjuncture, we examined scientific journals from before the Green Revolution of the 1950 s to analyze the general ideas about alternative agriculture at that time.

In order to assess the historical narrative of agriculture management, particular to North America, we utilized issues of the Canadian Journal ofScientific Agriculture, published between 1920 and 1940, paying particular attention to annual essays by journal editors. The articles were reviewed for general comments and observations on comparative agriculture and for recommendations for improvements or other changes to agricultural techniques. Relevant quotations were then used to form the general environmental narrative regarding alternative agriculture at the time.

In 1939, an article by Davidson (28), published in the Journal of Scientific Agriculture, speaking about conservation, said:

As a result of farming practices and as a result of 30 or 40 years of continuous production of soil-depleting crops, and in part, as a result of improper settlement policies, there are evidences of soil deterioration - evidences that new types of cropping will have to be utilized and that probably the technique of persistent wheat production will have to be altered in a measure at least. In so far as production policies now being carried on are resulting in an element for soil deterioration, it would seem that some active policy should be adopted to alter the situation. (16)

Davidson states in no uncertain terms that the conventional agricultural practices of the time were causing soil degradation and that alternative farming methods should be explored. Although Davidson does not suggest exactly what these alternative methods should include, he clearly outlines the perceived need for greater research on this topic.

In another article, Russel(29)argues that "...the cultivation of the soil [is] at least as important as the feeding of the crop."(29), indicating an awareness of the need for responsible tillage practices as a part of a sustainable farming regime dedicated to the maintenance of long-term soil fertility. Russel goes on to outline the need for further research, saying "Investigations are needed to find the best methods of increasing the supply of organic matter in the soil and its value for the different crops in the rotation" (36). This article clearly takes the view that there is a need for farming methods that increase and sustain organic matter levels in the soil, effectively predicting one of cornerstones of the organic farming systems being advocated for today.

Our review of the archival data also revealed an awareness on the part of agricultural researchers' of the limitations of crop management practices of that time period in terms of sustainable food production. An article by Newton (30) published in the Journal of Scientific Agriculture discussing the prospects for conventional agriculture in the United States reports

"The United States...has passed the era of great expansion in agricultural production... and has entered the era of diminishing returns, on the basis of present methods. The development of a permanent agriculture, on the basis of methods which prevent a deterioration in soil fertility will not make it possible...to support a population greater than 140 to 200 millionsat the standard of living which the country now enjoys." (229)

Leslie : learning from the present and the past

Newton identifies conventional agricultural methods as the reason behind falling crop yields and like Russel(29), he pushes for a 
more sustainable agriculture with the aim that includes maintenance of ecosystem integrity as opposed to strictly agricultural output. Later in the article, Newton writes "...the limit of improvement in yield of the English wheat crop with the knowledge now available appears to have been nearly reached." (231). These quotations indicate a clear understanding of the limits of the agricultural systems of the time to maintain a sustainable food supply through the maintenance of soil fertility over time.

This archival evidence points to a number of questions for potential further research on this topic. If the detrimental impacts of conventional agriculture were being documented by agriculturalists who were calling for more research into alternative practices, why was there still such a strong push for the development of intensive, conventional agriculture and why did the mainstreaming of organic practices in a North American context not begin to take place until recently? The archival data also raise questions about the viability of the current organic movement. If a small but influential group has been advocating for the use of alternative agriculture since the early $20^{\text {th }}$ century, how much hope is there that the current push for more sustainable practices will be any more effective. Perhaps the most important question of all is: once established, what will be required to ensure the persistence of said practices? These are questions that must be answered if alternative farming practices are to become the norm for agronomists.

We specifically chose to examine historical articles that were critical of conventional agricultural methods and our findings should not be taken to indicate that this was necessarily the popular view of the time. In fact, the opposite was true in that finding articles that questioned the use of conventional agriculture techniques was a difficult task. Nonetheless, this sample indicates that there was a group, however small, who were questioning the viability of the current methods and calling for further research into alternative agriculture.

\section{Conclusion}

Although the evidence supporting the use of alternative agriculture as a means by which to maintain soil fertility is growing, conventional agricultural techniques still maintain widespread use throughout the world. The response of proponents of alternative agriculture is growing ever more vocal, but change is slow. By historically contextualizing the current debate over the viability of alternative agriculture, we hoped to give a clearer understanding of its origins. Our findings indicate that the ideas being put forth today are not new arguments, but ones that have been discussed, in a North American context, by practitioners and scholars alike since at least the 1920s and likely even earlier. There is evidence that organic methods could produce enough food to significantly contribute to or even match the global food supply without increasing the agricultural land base. This significantly detracts from the strength of the argument that the popularity of conventional methods comes down to the necessity of food production. There is certainly hope for the alternative agriculture movement and for the wider adoption of agricultural techniques that value long-term ecosystem functions and soil fertility maintenance over shortterm production and financial gain. 


\section{REFERENCES}

Bengtsson J, Ahnstrom J, Weibull A. The effects of organic agriculture on biodiversity and abundance: a meta-analysis. Journal of Applied Ecoloy. 2005; 42: p. 261-269.

Duram LA, Larson KL. Agricultural research and alternative farmers' information needs. Professional Geographer. 2001; 53(1): p. 84-96

Evenson RE, Gollin D. Assessing the impact of the green revolution, 1960 to 2000. Science. 2003; 300(5620): p. 758-762.

Fliebach A, Oberholzer H, Gunst L, Mader P. Soil organic matter and biological soil quality indicators after 21 years of organic and conventional farming. Agriculture, Ecosystems and Environment. 2007; 118: p. 273-284.

Knorr D, Watkins TR, editors. In Alterations in food production. New York: Van Nostrand Reinhold; 1984

Kristiansen P. Overview of organic agriculture. In Kristiansen $\mathrm{P}$, Taji A, Reganold J, editors. Organic agriculture: a global perspective. Collingwood: CSIRO Publishing; 2006. p. 1-23.

Liebig MA, Doran JW. Impact of organic production practises on soil quality indicators. Journal of Environmental Quality. 1999; 28: p. 1601-1609.

Leonard TM, editor. Encyclopedia of the Developing World, Volume 1 New York: Routledge; 2006.

Merriam-Webster Inc. "alternative". In Merriam-Webster's Collegiate Dictionary. 11th ed.; 2003.

Murata T, Goh KM. Effects of cropping systems on soil organic matter in a pair of conventional and biodynamic mixed cropping farms in Canterbury, New Zealand. Biology and Fertility of Soils. 1997; 25: p. 372-381.

Oberson A, Fardeau JC, Besson JM, H S. Soil phosphorus dynamics in cropping syhstems managed according to the conventional and biological agricultural methods. Biology and fertility of soils. 1993; 16: p. 111-117.

United Nations (Rome). Food and Agriculture Association of the United Nations. [Online].; 1999 [cited 2010 March 4. Available from: HYPERLINK "http://www.fao.org/unfao.bodies. COAG/COAG15/X0075E.htm"htt p://www.fao.org/unfao.bodies.CO AG/COAG15/X0075E.htm.

Sherow JE. The grasslands of the United States: an environmental history California: ABC-CLIO Inc; 2007

Reganold JP, Palmer AS, C LJ, Macgregor AN. Soil quality and financial performance of biodynamic and conventional farms in New Zealand. Science. 1993; 260: p. 344-349.

Tong C, Xiao H, Tang G, Wang H, Huang $\mathrm{T}$, Xia $\mathrm{H}$, et al. Long term fertilizer effects on organic carbon and total nitrogen and coupling relationship sof $\mathrm{C}$ and $\mathrm{N}$ in paddy soils in sutropical China. Soil \& Tillage Research. 2009; 106: p. 8-14.

Walsh B. Getting real about the high price of cheap food. TIME. 2009 August; 174(8). 